\title{
Importance of Safety in the Management of Osteoarthritis and the Need for Updated Meta-Analyses and Recommendations for Reporting of Harms
}

\author{
Jean-Yves Reginster ${ }^{1,2,3}$ (D) Olivier Bruyère ${ }^{1,2} \cdot$ Philip G. Conaghan $^{4} \cdot$ Tim McAlindon $^{5} \cdot$ Cyrus Cooper $^{2,6,7}$ (I)
}

(c) The Author(s) 2019

Osteoarthritis (OA) is a chronic progressive disorder that typically requires multiple treatment modalities over the course of disease. Osteoarthritis occurs frequently in older age, and the incidence of $\mathrm{OA}$ is rising owing to an aging population and association with obesity [1]. Older patients often have comorbidities and are at an increased risk of cardiovascular, gastrointestinal (GI), and renal adverse events (AEs), which impact on the appropriate choice of anti-OA medication.

The contemporary model of evidence-based medicine is predicated on the principle that clinical decisions and recommendations are data driven. Recommendations are based on the balance of relative benefits and harms of the treatment and patients' values and preferences. Often, the choice of medication is reduced to a trade-off between desirable and undesirable outcomes.

While multiple guidelines exist for the treatment of OA [2-6], they contain varying levels of detail concerning the safety and side effects of OA therapies. Consequently, a summary of the current evidence base is timely. A working party was convened by the the European Society for Clinical and Economic Aspects of Osteoporosis, Osteoarthritis and

Jean-Yves Reginster

jyreginster@uliege.be

Olivier Bruyère

olivier.bruyere@uliege.be

Philip G. Conaghan

p.conaghan@leeds.ac.uk

Tim McAlindon

tmcalindon@tuftsmedicalcenter.org

Cyrus Cooper

cc@mrc.soton.ac.uk

1 Department of Public Health, Epidemiology and Health Economics, University of Liège, Liège, Belgium

2 WHO Collaborating Centre for Public Heath Aspects of Musculoskeletal Health and Aging, Liège, Belgium
Musculoskeletal Diseases (1 December, 2017) to discuss current knowledge on the safety of anti-OA medications. New systematic reviews and meta-analyses were presented by several members of the working party, and their research findings are reported in this supplement.

Paracetamol has long been widely used for analgesia in $\mathrm{OA}$; its widespread use is driven largely by an assumption of relative safety and despite evidence for its poor efficacy in OA. In recent years, evidence is mounting for cardiovascular, GI, renal, and hepatic AEs occurring with long-term paracetamol exposure. In this issue, Conaghan et al. provide a critical review of the literature on paracetamol safety, recommending a cautious approach to the use of paracetamol for chronic pain management in OA [7].

Non-steroidal anti-inflammatory drugs (NSAIDs) play a central role in the management of pain in OA. While moderately effective on OA pain, NSAIDs are associated with wide-ranging toxicities affecting the GI, cardiovascular, and renal systems. In a narrative literature review, Cooper et al. [8] provide a synopsis of safety data on non-selective NSAIDs published since the Cochrane review of 2011 [9]. Gastrointestinal toxicity is found with all NSAIDs, which

3 Chair for Biomarkers of Chronic Diseases, Biochemistry Department, College of Science, King Saud University, Riyadh, Kingdom of Saudi Arabia

4 Leeds Institute of Rheumatic and Musculoskeletal Medicine, University of Leeds and National Institute for Health Research Leeds Biomedical Research Centre, Leeds Teaching Hospitals NHS Trust, Leeds, UK

5 Division of Rheumatology, Tufts Medical Center, Boston, MA, USA

6 MRC Lifecourse Epidemiology Unit, Southampton General Hospital, University of Southampton, Southampton, UK

7 Musculoskeletal Biomedical Research Unit, National Institute for Health Research (NIHR), University of Oxford, Oxford, UK 
may be of particular concern when treating older patients with OA. Cardiovascular toxicity is associated with all NSAIDs to some extent and the degree of risk appears to be drug specific. All NSAIDs have the potential to induce acute kidney injury, and patients with OA with co-morbid conditions including diabetes mellitus, hypertension, and heart failure are at increased risk. Further details provided in this analysis will facilitate a better understanding of the risk:benefit of using NSAIDs in OA and aid treatment selection.

In an accompanying article, Curtis et al. present the results of a systematic literature review and meta-analysis of the safety of cyclo-oxygenase (COX)-2 inhibitors [10]. Although the COX-2 inhibitors were designed to avoid the GI toxicity associated with COX-1 inhibition and non-selective NSAIDs, the results of this meta-analysis show that an increased risk of upper GI AEs, especially abdominal pain, remains with the COX-2 selective inhibitor class. Cyclo-oxygenase-2 inhibitors have a known association with increased risk of cardiovascular AEs; notably, even with the removal of rofecoxib from this meta-analysis, the risk of heart failure and edema remained significant. Consequently, a cautious approach to the use of NSAIDs and COX-2 inhibitors in $\mathrm{OA}$ is advised, with selection of treatment tailored to the individual patient characteristics, and limited to intermittent or cyclical use rather than long-term treatment to minimize safety concerns.

Topical NSAIDs are generally recommended ahead of oral NSAIDs as an early option for the symptomatic management of OA. Topical NSAIDs have a moderate effect on pain with similar efficacy to oral NSAIDs, but with a better safety profile owing to lower systemic absorption [9]. The findings of a systematic literature review and meta-analysis presented by Honvo et al. in this issue confirm the favorable safety profile of the topical route of administration of NSAIDs [11]. A non-significant increase in skin and subcutaneous tissue disorders was found, largely driven by topical diclofenac, which may account for the higher withdrawal rate with topical NSAIDs vs. placebo. Nonetheless, topical NSAIDs may be considered as safe in the management of OA, especially with regard to low GI toxicity.

Symptomatic slow-acting drugs for OA (SYSADOAs) represent a class of diverse agents that offer benefit in managing the symptoms of OA, with evidence for a diseasemodifying effect in the long term in some cases [12-14]. Symptomatic slow-acting drugs for OA include glucosamine sulfate, chondroitin sulfate, diacerein, and avocado soybean unsaponifiables, which are widely used and it is of primary importance to establish their safety profiles. While some SYSADOAs may be considered safe for use in patients with $\mathrm{OA}$, some concerns have been raised about the safety profiles of other agents. Consequently, Honvo et al. have performed a systematic review and meta-analysis of the safety of SYSADOAs vs. placebo in OA, the findings of which are reported in this issue [15]. The SYSADOAs glucosamine sulfate and chondroitin sulfate are shown to be safe treatments for patients with OA. Indeed, only the pharmaceutical-grade prescription crystalline glucosamine sulfate and chondroitin sulfate are recommended as safe and effective SYSADOAs $[2,16]$. Limited evidence is available for unsaponifiables, which comprise multiple products containing a complex mixture of many natural vegetable extracts; however, the safety of one proprietary product is demonstrated in this new analysis. Diacerein is also available in several products and is associated with some safety signals [17]; consequently, the usefulness of diacerein in OA should be assessed for each patient after consideration of the nature of the product, appropriate dosage, and patient characteristics [18].

Intra-articular hyaluronic acid (IAHA) is recommended as a treatment option in the case of a contraindication to NSAIDs, e.g., in older patients with comorbidities, and patients who did not respond to earlier treatment [2]. Despite mounting evidence for the efficacy of IAHA, particularly for knee OA, and the widespread use of IAHA in clinical practice, controversy still persists regarding the risk:benefit of IAHA largely because of mixed reports on safety. The findings of a systematic review and meta-analysis presented in this issue by Honvo et al. did not identify any safety issue with IAHA [19], although the evidence was associated with only "low" to "moderate" certainty owing to a lack of safety data reporting for IAHA, which requires further studies. It is possible that some reports of serious AEs associated with IAHA are due to the concomitant use of NSAIDs, which should be further investigated.

The use of opioid analgesia may be considered as a lastresort pharmacologic therapy in OA when the pain is severe, when patients have not responded to other therapies, and when surgery is not deemed appropriate [2]. The results of a systematic review and meta-analysis presented here by Fuggle et al. confirm that there are considerable safety and tolerability issues surrounding the use of opioids in OA [20]. Oral opioids are associated with an increased risk of GI-, dermatologic-, and central nervous system-related AEs, regardless of whether the immediate- or extended-release formulation is used. These findings support recommendations to use opioids in OA after other analgesic options and only for short time periods.

Last, in preparation of the meta-analyses of the safety of anti-OA medications, the extensive literature review revealed a lack of reporting of $\mathrm{AE}$ data and inconsistencies in the data reported. This identified a need for precise disease-specific guidance on the reporting of AEs in clinical trial manuscripts. To close this gap, a consensus statement from the European Society for Clinical and Economic Aspects of Osteoporosis, Osteoarthritis and Musculoskeletal 
Diseases Working Group published in this supplement provides specific, clear, practical, and standardized guidance on the reporting of $\mathrm{AE}$ data in manuscripts reporting the outcomes of clinical trials assessing drugs for OA [21], which will complement existing recommendations [22-24]. Ultimately, we hope that the findings of these new safety analyses will add to the evidence base from which future guideline updates may provide further clarity on the appropriate selection of anti-OA medications tailored to the individual patient.

\begin{abstract}
Acknowledgements This paper is written on behalf of the European Society for Clinical and Economic Aspects of Osteoporosis, Osteoarthritis and Musculoskeletal Diseases (ESCEO) Working Group on the safety of anti-osteoarthritis medications: Nasser Al-Daghri, Nigel Arden, Bernard Avouac, Olivier Bruyère, Roland Chapurlat, Philip Conaghan, Cyrus Cooper, Elizabeth Curtis, Elaine Dennison, Nicholas Fuggle, Gabriel Herrero-Beaumont, Germain Honvo, Margreet Kloppenburg, Stefania Maggi, Tim McAlindon, Alberto Migliore, Ouafa Mkinsi, François Rannou, Jean-Yves Reginster, René Rizzoli, Roland Roth, Thierry Thomas, Daniel Uebelhart, and Nicola Veronese. Philip G. Conaghan is supported in part by the UK National Institute for Health Research Leeds Biomedical Research Centre. The views expressed in this publication are those of the author(s) and not necessarily those of the National Health Service, the National Institute for Health Research, or the Department of Health. The authors express their most sincere gratitude to Dr. Lisa Buttle for her invaluable help with the manuscript preparation. Dr. Lisa Buttle was entirely funded by the ESCEO asbl, Belgium.
\end{abstract}

\section{Compliance with Ethical Standards}

All authors meet the International Committee of Medical Journal Editors criteria for authorship for this manuscript, take responsibility for the integrity of the work as a whole, and have given final approval to the version to be published.

Funding The working group was entirely funded by the ESCEO, a Belgian not-for-profit organization. The ESCEO receives unrestricted educational grants, to support its educational and scientific activities, from non-governmental organizations, not-for-profit organizations, and non-commercial and corporate partners. The choice of topics, participants, content, and agenda of the working groups as well as the writing, editing, submission, and reviewing of the manuscript are under the sole responsibility of the ESCEO, without any influence from third parties.

Conflict of interest Olivier Bruyère reports grants from Biophytis, IBSA, MEDA, Servier, SMB, and Theramex, outside of the submitted work. Cyrus Cooper reports personal fees from Alliance for Better Bone Health, Amgen, Eli Lilly, GlaxoSmithKline, Medtronic, Merck, Novartis, Pfizer, Roche, Servier, Takeda, and UCB, outside of the submitted work. Jean-Yves Reginster reports grants from IBSA-Genevrier, Mylan, CNIEL, and Radius Health (through institution), consulting fees from IBSA-Genevrier, Mylan, CNIEL, Radius Health, and Pierre Fabre, fees for participation in review activities from IBSA-Genevrier, MYLAN, CNIEL, Radius Health, and Teva, and payment for lectures from AgNovos, CERIN, CNIEL, Dairy Research Council (DRC), Echolight, IBSA-Genevrier, Mylan, Pfizer Consumer Health, Teva, and Theramex, outside of the submitted work. Philip G. Conaghan reports consultancy fees or speakers' bureaus from Abbvie, BMS, Flexion Therapeutics, GlaxoSmithKline, Merck Serono, Novartis, Pfizer,
Roche, and Samumed, outside of the submitted work. Tim McAlindon reports fees for participation in review activities from Pfizer, and fees for consulting activities with Flexion, Samumed, Sanofi, Visgo, Roche, Astellas, Pfizer, Seikayaku, Regeneron, and Anika, outside of the submitted work.

Open Access This article is distributed under the terms of the Creative Commons Attribution-NonCommercial 4.0 International License (http://creativecommons.org/licenses/by-nc/4.0/), which permits any noncommercial use, distribution, and reproduction in any medium, provided you give appropriate credit to the original author(s) and the source, provide a link to the Creative Commons license, and indicate if changes were made.

\section{References}

1. Bijlsma JW, Berenbaum F, Lafeber FP. Osteoarthritis: an update with relevance for clinical practice. Lancet. 2011;377(9783):211526. https://doi.org/10.1016/S0140-6736(11)60243-2.

2. Bruyere O, Cooper C, Pelletier JP, Branco J, Brandi ML, Guillemin $\mathrm{F}$, et al. An algorithm recommendation for the management of knee osteoarthritis in Europe and internationally: a report from a task force of the European Society for Clinical and Economic Aspects of Osteoporosis and Osteoarthritis (ESCEO). Semin Arthritis Rheum. 2014;44(3):253-63. https://doi.org/10.1016/j. semarthrit.2014.05.014.

3. McAlindon TE, Bannuru RR, Sullivan MC, Arden NK, Berenbaum F, Bierma-Zeinstra SM, et al. OARSI guidelines for the non-surgical management of knee osteoarthritis. Osteoarthr Cartil. 2014;22(3):363-88. https://doi.org/10.1016/j.joca.2014.01.003.

4. Hochberg MC, Altman RD, April KT, Benkhalti M, Guyatt G, McGowan J, et al. American College of Rheumatology 2012 recommendations for the use of nonpharmacologic and pharmacologic therapies in osteoarthritis of the hand, hip, and knee. Arthritis Care Res. 2012;64(4):465-74. https://doi.org/10.1002/ acr.21596.

5. National Institute for Health and Care Excellence. Osteoarthritis care and management in adults: methods, evidence and recommendations. National Clinical Guideline Centre. London: National Institute for Health and Care Excellence; Feb 2014: Report no. CG177.

6. Jordan KM, Arden NK, Doherty M, Bannwarth B, Bijlsma JWJ, Dieppe P, et al. EULAR Recommendations 2003: an evidence based approach to the management of knee osteoarthritis: Report of a Task Force of the Standing Committee for International Clinical Studies Including Therapeutic Trials (ESCISIT). Ann Rheum Dis. 2003;62(12):1145-55. https://doi.org/10.1136/ ard.2003.011742.

7. Conaghan PG, Arden N, Avouac B, Migliore A, Rizzoli R. Safety of paracetamol: what does the literature say? Drugs Aging. 2019;36(Suppl. 1). https://doi.org/10.1007/s40266-019-00658-9.

8. Cooper C, Chapurlat R, Al-Daghri N, Herrero-Beaumont G, Bruyere O, Rannou F, et al. Safety of oral non-selective nonsteroidal anti-inflammatory drugs: what does the literature say? Drugs Aging. 2019;36(Suppl. 1). https://doi.org/10.1007/s4026 6-019-00660-1.

9. Chou R, McDonagh MS, Nakamoto E, Griffin J. Analgesics for osteoarthritis: an update of the 2006 comparative effectiveness review. Comparative effectiveness review no. 38. October 2011. AHRQ publication no. 11(12)-EHC076-EF. Rockville (MD): Agency for Healthcare Research and Quality. http://www.ncbi. 
nlm.nih.gov/pubmedhealth/PMH0016485/pdf/TOC.pdf. Accessed 27 Apr 2018

10. Curtis E, Fuggle N, Shaw S, Spooner L, Ntani G, Parsons C, et al. Safety of cyclo-oxygenase-2 inhibitors in osteoarthritis: outcomes of a systematic review and meta-analysis. Drugs Aging. 2019;36(Suppl. 1). https://doi.org/10.1007/s40266-019-00664-x.

11. Honvo G, Leclercq V, Geerinck A, Thomas T, Veronese N, Charles A, et al. Safety of topical non-steroidal anti-inflammatory drugs in osteoarthritis: outcomes of a systematic review and metaanalysis. Drugs Aging. 2019;36(Suppl. 1). https://doi.org/10.1007/ s40266-019-00661-0.

12. Bartels EM, Bliddal H, Schondorff PK, Altman RD, Zhang W, Christensen R. Symptomatic efficacy and safety of diacerein in the treatment of osteoarthritis: a meta-analysis of randomized placebo-controlled trials. Osteoarthr Cartil. 2010;18(3):289-96. https://doi.org/10.1016/j.joca.2009.10.006.

13. Towheed TE, Maxwell L, Anastassiades TP, Shea B, Houpt J, Robinson V, et al. Glucosamine therapy for treating osteoarthritis. Cochrane Database Syst Rev. 2009;2:CD002946. https://doi. org/10.1002/14651858.cd002946.pub2.

14. Singh JA, Noorbaloochi S, MacDonald R, Maxwell LJ. Chondroitin for osteoarthritis. Cochrane Database Syst Rev. 2015. https:// doi.org/10.1002/14651858.cd005614.pub2.

15. Honvo G, Reginster J-Y, Rabenda V, Geerinck A, Mkinsi O, Charles A, et al. Safety of symptomatic slow-acting drugs for osteoarthritis: outcomes of a systematic review and meta-analysis. Drugs Aging. 2019;36(Suppl. 1). https://doi.org/10.1007/s4026 6-019-00662-z.

16. Bruyere O, Cooper C, Al-Daghri NM, Dennison EM, Rizzoli R, Reginster JY. Inappropriate claims from non-equivalent medications in osteoarthritis: a position paper endorsed by the European Society for Clinical and Economic Aspects of Osteoporosis, Osteoarthritis and Musculoskeletal Diseases (ESCEO). Aging Clin Exp Res. 2017;30(2):111-7. https://doi.org/10.1007/s4052 0-017-0861-1.

17. Pelletier JP, Martel-Pelletier J. Diacerein-containing products: same risk of diarrhoea? Aging Clin Exp Res. 2018;30(4):411-2. https://doi.org/10.1007/s40520-018-0911-3.
18. Pavelka K, Bruyere O, Cooper C, Kanis JA, Leeb BF, Maheu $\mathrm{E}$, et al. Diacerein: benefits, risks and place in the management of osteoarthritis. An opinion-based report from the ESCEO. Drugs Aging. 2016;33(2):75-85. https://doi.org/10.1007/s4026 6-016-0347-4.

19. Honvo G, Reginster JY, Rannou F, Rygaert X, Geerinck A, Rabenda V, et al. Safety of intra-articular hyaluronic acid injections in osteoarthritis: outcomes of a systematic review and metaanalysis. Drugs Aging. 2019;36(Suppl. 1). https://doi.org/10.1007/ s40266-019-00657-w.

20. Fuggle N, Curtis E, Shaw S, Spooner L, Bruyere O, Ntani G, et al. Safety of opioids in osteoarthritis: outcomes of a systematic review and meta-analysis. Drugs Aging. 2019;36(Suppl. 1). https ://doi.org/10.1007/s40266-019-00666-9.

21. Honvo G, Bannuru RR, Bruyere O, Rannou F, Herrero-Beaumont $\mathrm{G}$, Uebelhart $\mathrm{D}$, et al. Recommendations for the reporting of harms in manuscripts on clinical trials assessing osteoarthritis drugs: a consensus statement from the European Society for Clinical and Economic Aspects of Osteoporosis, Osteoarthritis and Musculoskeletal Diseases (ESCEO). Drugs Aging. 2019;36(Suppl. 1). https://doi.org/10.1007/s40266-019-00667-8.

22. Ioannidis JP, Evans SJ, Gotzsche PC, O’Neill RT, Altman DG, Schulz K, et al. Better reporting of harms in randomized trials: an extension of the CONSORT statement. Ann Intern Med. 2004;141(10):781-8.

23. Lineberry N, Berlin JA, Mansi B, Glasser S, Berkwits M, Klem $\mathrm{C}$, et al. Recommendations to improve adverse event reporting in clinical trial publications: a joint pharmaceutical industry/journal editor perspective. BMJ. 2016;355:i5078. https://doi.org/10.1136/ bmj.i5078.

24. McAlindon TE, Driban JB, Henrotin Y, Hunter DJ, Jiang GL, Skou ST, et al. OARSI clinical trials recommendations: design, conduct, and reporting of clinical trials for knee osteoarthritis. Osteoarthr Cartil. 2015;23(5):747-60. https://doi.org/10.1016/j. joca.2015.03.005. 